\title{
Potencial germinativo e morfoanatomia foliar de plântulas de pinhão-manso originadas de germoplasma criopreservado
}

\author{
Rafael de Carvalho Silva(1), Julceia Camillo(2), Zanderluce Gomes Luis(2) \\ e Jonny Everson Scherwinski-Pereira ${ }^{(3)}$
}

\begin{abstract}
(1) Universidade Federal do Amazonas, Avenida General Rodrigo Octávio Jordão Ramos, no 3.000 , Bairro Coroado I, CEP 69057-070 Manaus, AM. E-mail: carvalho_fael@yahoo.com.br (2)Universidade de Brasília, Campus Universitário Darcy Ribeiro, CEP 70910-900 Brasília, DF. E-mail: camillo@gmail.com, zanbio@hotmail.com ${ }^{(3)}$ Embrapa Recursos Genéticos e Biotecnologia, Avenida W5 Norte (Final), CEP 70770-917 Brasília, DF. E-mail: jonny@cenargen.embrapa.br
\end{abstract}

Resumo - O objetivo deste trabalho foi avaliar o potencial germinativo e caracterizar morfoanatomicamente a estrutura foliar de plântulas de pinhão-manso originadas de germoplasma criopreservado. Inicialmente, as sementes foram avaliadas quanto à dessecação, a cada 24 horas, por até 120 horas. Posteriormente, as sementes foram dessecadas por 0,24 e 48 horas e avaliadas mensalmente quanto ao potencial germinativo, antes e após armazenamento em nitrogênio líquido por imersão direta e congelamento rápido. Para caracterizar a viabilidade das sementes que não germinaram após o período de avaliação, os embriões zigóticos foram imersos em solução de tetrazólio. A morfoanatomia foliar após criopreservação foi caracterizada por meio de estudos histológicos. As sementes de pinhão-manso toleraram a dessecação a níveis críticos e a criopreservação com umidade em torno de $8 \%$. A dessecação das sementes até valores baixos, associada a períodos prolongados de exposição ao nitrogênio líquido, causa anormalidade de plântulas, danifica as células e os tecidos das folhas, e afeta negativamente a germinação.

Termos para indexação: Jatropha curcas, conservação ex situ, criopreservação, dessecação, fisiologia de sementes, tolerância.

\section{Germinative potential and leaf morphoanatomy of physic nut seedlings from cryopreserved germplasm}

\begin{abstract}
The objective of this work was to evaluate the germinative potential and the morphoanatomical features of leaves in seedlings of physic nut from cryopreserved germplasm. Initially, seeds were evaluated regarding desiccation every 24 hours for up to 120 hours. Then, seeds were desiccated for 0,24 , and 48 hours, and evaluated monthly as to germinative potential, before and after storage in liquid nitrogen by direct immersion and fast freezing. To characterize the viability of seeds that did not germinate after the evaluation period, the zygotic embryos were immersed in tetrazolium solution. Morphoanatomical features of leaves were determined after cryopreservation by histological evaluation. Physic nut seeds tolerated desiccation to critical levels and cryopreservation with moisture content around 8\%. Seed desiccation to lower values, associated with longer periods of exposition to liquid nitrogen, causes abnormalities in seedlings, damages leaf cells and tissues, and affects negatively germination.
\end{abstract}

Index terms: Jatropha curcas, ex situ conservation, cryopreservation, desiccation, seed physiology, tolerance.

\section{Introdução}

O gênero Jatropha (Euphorbiaceae), com distribuição nas regiões semiáridas tropicais da África e das Américas, é representado por mais de 170 espécies (Webster, 1994). Entre elas, o pinhão-manso (Jatropha curcas L.) destaca-se por apresentar alto teor de óleo (30-40\%) nas sementes, e conter ácido palmítico, ácido oleico e ácido linoleico (Berchmans \& Hirata, 2008). Portanto, há crescente interesse no cultivo da espécie para a produção de biodiesel, principalmente nas regiões semiáridas, por se tratar de um arbusto perene, tolerante à seca. Contudo, a ausência de cultivares melhoradas e a falta de conhecimento de aspectos fisiológicos das sementes, inclusive quanto à conservação de germoplasma, dificultam o desenvolvimento da cadeia produtiva dessa espécie (Openshaw, 2000; Carvalho et al., 2008).

Acessos de $J$. curcas são, frequentemente, mantidos em coleções em campo (Heller, 1996), o que requeráreas extensas, mão de obra intensiva e recursos contínuos. Esses acessos estão constantemente sob risco de

Pesq. agropec. bras., Brasília, v.46, n.8, p.836-844, ago. 2011 
serem perdidos, por causa de adversidades ambientais, ataques de pragas, dificuldades de multiplicação e limitações orçamentárias, especialmente em países em desenvolvimento. Além disso, o potencial dessa espécie em disseminar pragas e doenças é uma limitação importante no intercâmbio de germoplasma (Engelmann, 2009).

Para fins de conservação e viabilidade, as sementes podem ser classificadas como recalcitrantes, ortodoxas ou intermediárias e podem ser conservadas ex situ, sob temperatura de $-20^{\circ} \mathrm{C}$, e por criopreservação $\left(-196^{\circ} \mathrm{C}\right)$, o que diminui a níveis mínimos o metabolismo das sementes e evita a deterioração do material biológico (Roberts, 1973; Hoekstra et al., 2001).

Diversas técnicas vêm sendo utilizadas para a criopreservação de diferentes partes vegetativas, como embriões somáticos e zigóticos, meristemas, calos e gemas. Porém, as sementes são mais adequadas para fins de conservação de uma espécie, por serem sistemas mais organizados. Entretanto, seu elevado teor de umidade dificulta a criopreservação, pois pode haver morte instantânea do material ao ser submetido ao nitrogênio líquido. Estudos sobre a relação entre os teores de umidade e o tempo de armazenamento, em diferentes espécies, mostram que não há um valor de umidade específico determinante, mas um intervalo de valores aceitáveis para o congelamento. Esse intervalo varia em cada espécie; contudo, recomenda-se, para sementes, conteúdos de umidade abaixo de 10\% (Roberts, 1973; Kermode \& Finch-Savage, 2002).

No Brasil, a ausência de cultivares geneticamente melhoradas tem sido um dos fatores que dificultam a expansão na cadeia produtiva do pinhão-manso, para a produção de biodiesel (Saturnino et al., 2005). Tem-se buscado desenvolver cultivares adaptadas às diversas condições edafoclimáticas, com alta produtividade e qualidade de óleo. Nesse sentido, a disponibilidade de germoplasma conservado para subsidiar programas de melhoramento genético é um fator condicionante para a expansão do setor. No entanto, são escassos os trabalhos a respeito do comportamento fisiológico das sementes de pinhão-manso sob condições de conservação, e não há conhecimento de estudos sobre sua tolerância à criopreservação.

O objetivo deste trabalho foi avaliar o potencial germinativo e caracterizar morfoanatomicamente a estrutura foliar de plântulas de pinhão-manso originadas de germoplasma criopreservado.

\section{Material e Métodos}

Os frutos de pinhão-manso avaliados foram colhidos no Município de Janaúba, MG. A colheita dos frutos foi realizada a partir de amostra composta de plantas adultas que apresentavam frutos secos e deiscentes, de coloração marrom escura. Após a coleta e a extração manual das sementes, em laboratório, avaliou-se o teor de água inicial, pelo método adaptado de estufa a $105 \pm 3^{\circ} \mathrm{C}$ por 24 horas (Regras para análise de sementes, 2009), tendo-se utilizado três repetições com cinco sementes cada uma.

Após a avaliação do teor inicial de água, foram determinados a curva de dessecação das sementes e o efeito imediato desta sobre a germinação das sementes. Para obtenção da curva de dessecação, foram coletadas amostras de sementes após $0,24,48,72,96$ e 120 horas de permanência sobre sílica-gel, analisadas quanto ao teor de água e germinação. Em seguida, o tegumento foi removido e os endospermas foram esterilizados em câmara de fluxo laminar, por imersão do material em etanol a $70 \%$ por $1 \mathrm{~min}$, seguido de 15 min em solução de hipoclorito de sódio (alvejante comercial a $50 \%$, com 2,0 a $2,5 \%$ de cloro ativo) e tríplice lavagem em água destilada e autoclavada. As sementes foram colocadas para germinar em meio de cultura MS (Murashige \& Skoog, 1962), e o pH do meio foi ajustado para 5,7 70,1 antes da autoclavagem. Para germinação, as sementes foram mantidas em sala de crescimento com temperatura de $25 \pm 2^{\circ} \mathrm{C}$, sob fotoperíodo de 16 horas com radiação luminosa de $30 \mathrm{mmol} \mathrm{m}^{-2} \mathrm{~s}^{-1}$.

Aos 30 dias após a semeadura, a germinação foi avaliada a cada três dias, e os resultados finais foram expressos em percentagem. Juntamente com o teste de germinação, foi avaliado o índice de velocidade de germinação (IVG). Para estimar o IVG, utilizou-se a equação de Edmond \& Drapala (1958):

$\mathrm{IVG}=\left(\mathrm{N}_{1} \mathrm{G}_{1}+\mathrm{N}_{2} \mathrm{G}_{2}+\ldots+\mathrm{N}_{\mathrm{n}} \mathrm{G}_{\mathrm{n}}\right) /(\mathrm{G} 1+\mathrm{G} 2+\ldots+\mathrm{Gn})$,

em que: $G_{1}, G_{2} \ldots G_{n}$ equivale ao número de sementes germinadas no dia da observação, e $\mathrm{N}_{1}, \mathrm{~N}_{2} \ldots \mathrm{N}_{\mathrm{n}}$ é o número de dias após a semeadura.

Utilizou-se o delineamento experimental inteiramente casualizado, com seis tratamentos (umidades das sementes) e quatro repetições. Cada parcela foi constituída por 20 sementes. Os resultados obtidos foram submetidos à análise de variância, e as médias

Pesq. agropec. bras., Brasília, v.46, n.8, p.836-844, ago. 2011 
foram comparadas pelo teste de Tukey, a 5\% de probabilidade.

Após a determinação da curva de dessecação, as sementes foram divididas em sublotes e depositadas sobre sílica-gel para dessecação por 0,24 e 48 horas. A testemunha $\mathrm{e}$ as sementes dessecadas foram avaliadas quanto ao poder germinativo antes e após armazenamento em nitrogênio líquido $(+\mathrm{NL})$. Para o congelamento, as sementes foram acondicionadas em envelopes aluminizados trifoliolados (polietileno-alumínio-polietileno) e expostas ao nitrogênio líquido, por imersão direta e congelamento rápido. As sementes ficaram armazenadas por até 90 dias, e foram feitas avaliações mensais aos 0,60 e 90 dias de armazenamento. O descongelamento das sementes foi realizado à temperatura ambiente $\left(25 \pm 2^{\circ} \mathrm{C}\right)$ por 16 horas. Tanto a desinfestação superficial quanto a composição do meio de cultura usado para a germinação das sementes seguiram o mesmo protocolo usado anteriormente.

Foram avaliados mensalmente a percentagem de germinação, a altura das plântulas, o número de raízes e a percentagem de plântulas anormais. Considerou-se como germinação a protusão da radícula acompanhada por curvatura geotrópica. Para avaliar a viabilidade das sementes que não germinaram após o período de avaliação, as sementes foram cortadas, e os embriões zigóticos foram imersos em solução de tetrazólio a $0,75 \%$ e mantidos no escuro a $40^{\circ} \mathrm{C}$, por 24 horas.

As anormalidades nas plântulas após o congelamento das sementes foram avaliadas por meio de cortes anatômicos nas folhas, de acordo com metodologia adaptada de Pacheco et al. (1998). Para tanto, o material vegetal foi imerso em solução fixadora Karnovsky, composta de paraformaldeído a $4 \%$, glutaraldeído a $2,5 \%$ e tampão cacodilato de sódio a $0,05 \mathrm{~mol} \mathrm{~L}^{-1}$, sob vácuo, por 24 horas. Em seguida, as amostras foram desidratadas em série alcoólica crescente, infiltradas e incluídas em historresina (Leica). Cortes transversais foram obtidos em micrótomo rotatório e corados com azul de toluidina. Os resultados foram registrados em fotomicroscópio Zeiss, modelo Axioskop (Carl Zeiss Company, Oberkochen, Baden-Württemberg, Alemanha), acoplado a um sistema digital de captura de imagens ImagePro (Media Cybernetics, 2001).

$\mathrm{Na}$ criopreservação, utilizou-se o delineamento experimental inteiramente casualizado, em esquema fatorial $3 \times 4$, com três tempos de dessecação $(0,24$ e 48 horas) e quatro períodos de criopreservação ( 0 , 30, 60 e 90 dias). Os resultados foram submetidos à análise de regressão com uso do programa estatístico Sanest (Zonta \& Machado, 1984). Os dados expressos em percentagem (x) foram transformados para arc sen $(\mathrm{x} / 100)^{0,5}$, e os dados da variável número de raízes foram transformados para $(\mathrm{x}+0,5)^{0,5}$. Os resultados da variável altura não foram transformados.

\section{Resultados e Discussão}

Agerminação das sementes de pinhão-manso ocorreu a partir do terceiro dia após a inoculação in vitro, seguida de crescente aumento na germinação após a semeadura e de estabilidade após 21 dias de avaliação (Figura 1). A dessecação das sementes de $J$. curcas não influenciou significativamente a percentagem de germinação (Tabela 1). O lote de sementes mantido por 120 horas sob sílica-gel apresentou 2,4\% de umidade, e não foi observada diferença significativa quanto à percentagem de germinação $(76,2 \%)$, em comparação

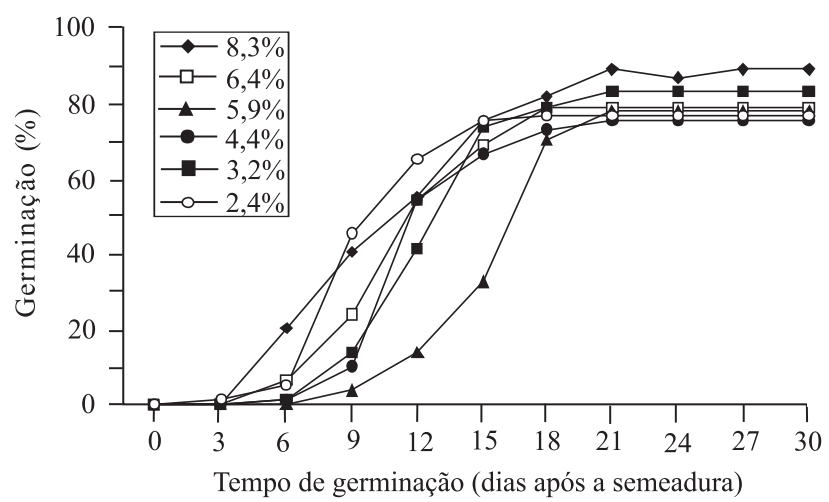

Figura 1. Germinação de sementes de pinhão-manso (Jatropha curcas), de acordo com o tempo de germinação e teor de umidade da semente.

Tabela 1. Germinação e índice de velocidade de germinação (IVG), em função do teor de umidade em sementes de pinhão-manso ${ }^{(1)}$.

\begin{tabular}{lcl}
\hline Teor de umidade (\%) & Germinação (\%) & IVG (dias) \\
\hline 8,3 & $88,7 \mathrm{a}$ & $20,3 \mathrm{a}$ \\
6,4 & $78,7 \mathrm{a}$ & $22,2 \mathrm{bc}$ \\
5,9 & $77,5 \mathrm{a}$ & $23,5 \mathrm{c}$ \\
4,4 & $75,0 \mathrm{a}$ & $21,1 \mathrm{ab}$ \\
3,2 & $82,5 \mathrm{a}$ & $21,5 \mathrm{ab}$ \\
2,4 & $76,2 \mathrm{a}$ & $20,0 \mathrm{a}$ \\
\hline
\end{tabular}

${ }^{(1)}$ Médias seguidas de letras iguais, dentro de cada variável, não diferem entre si pelo teste de Tukey, a $5 \%$ de probabilidade. 
ao lote testemunha $(88,7 \%)$ (umidade inicial, sem dessecação). De acordo com Black et al. (2002), a tolerância das sementes à dessecação pode ser definida como a capacidade de recuperar as funções biológicas após desidratação.

O tempo necessário para determinado lote de sementes germinar depende da espécie avaliada e das condições ambientais nas quais se encontra (Ferreira $\&$ Borghetti, 2004). Neste trabalho, maior velocidade de germinação ocorreu entre o vigésimo e o vigésimo terceiro dia. O lote de sementes com umidade de $5,9 \%$ apresentou o maior tempo para estabilizar a germinação, enquanto os lotes com umidade de 8,3 e 2,4\% apresentaram a maior velocidade de germinação (Tabela 1). Carvalho \& Müller (1998) também verificaram aumento do tempo requerido para germinação das sementes de pupunha (Bactris gasipaes Kunth) à medida que ocorreu a dessecação.

As curvas de germinação apresentaram padrão sigmoide, o que pode ser explicado pela estabilidade
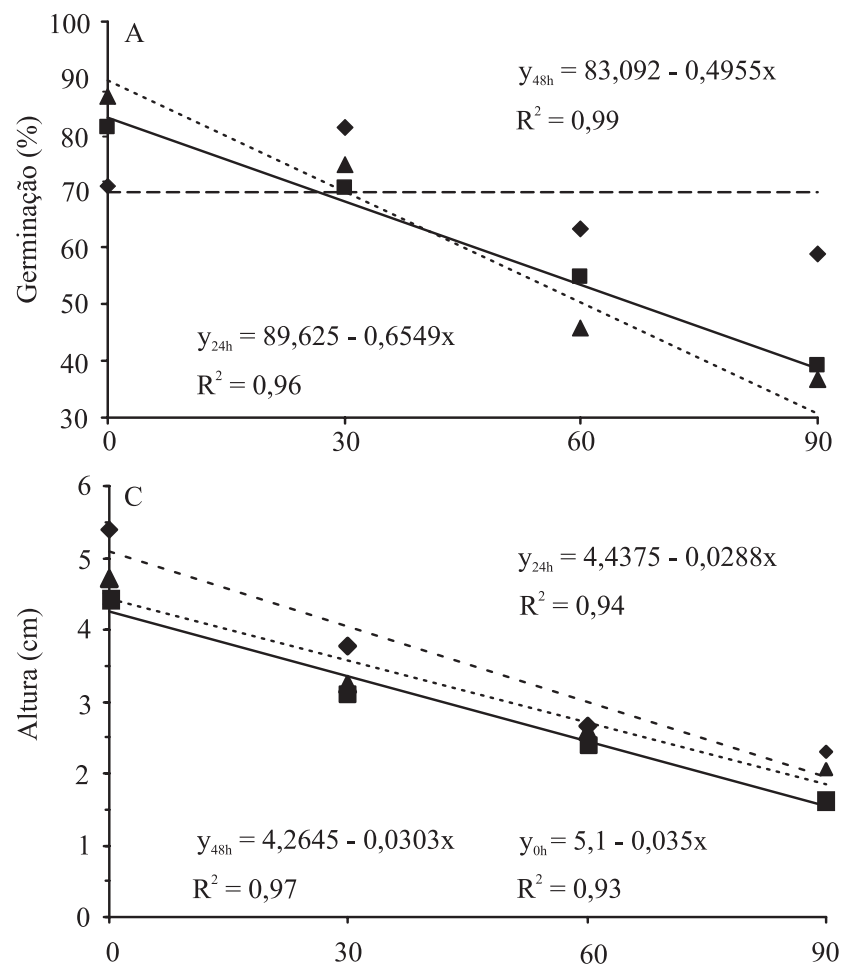

das sementes germinadas após dessecação (Figura 1). Entretanto, de maneira geral, a dessecação das sementes causou retardamento no início da germinação, o que é indicação de que as sementes de pinhão-manso toleram até $2,4 \%$ de umidade e apresentam comportamento de sementes ortodoxas.

A umidade inicial do lote de sementes de pinhão-manso foi de 8,3\% e, na ausência de dessecação, não foi observado efeito significativo dos períodos de criopreservação sobre a percentagem de germinação (Figura 2). Esse efeito tornou-se evidente a partir da dessecação das sementes por 24 horas $(6,4 \%$ de umidade). Quanto ao lote de sementes dessecadas por 48 horas (5,9\% de umidade), observou-se queda na percentagem de germinação de 81,9 para $37 \%$, entre os períodos de criopreservação. Isto é uma indicação de que a dessecação das sementes, associada a períodos prolongados (90 dias) em nitrogênio líquido, afeta negativamente sua sobrevivência.
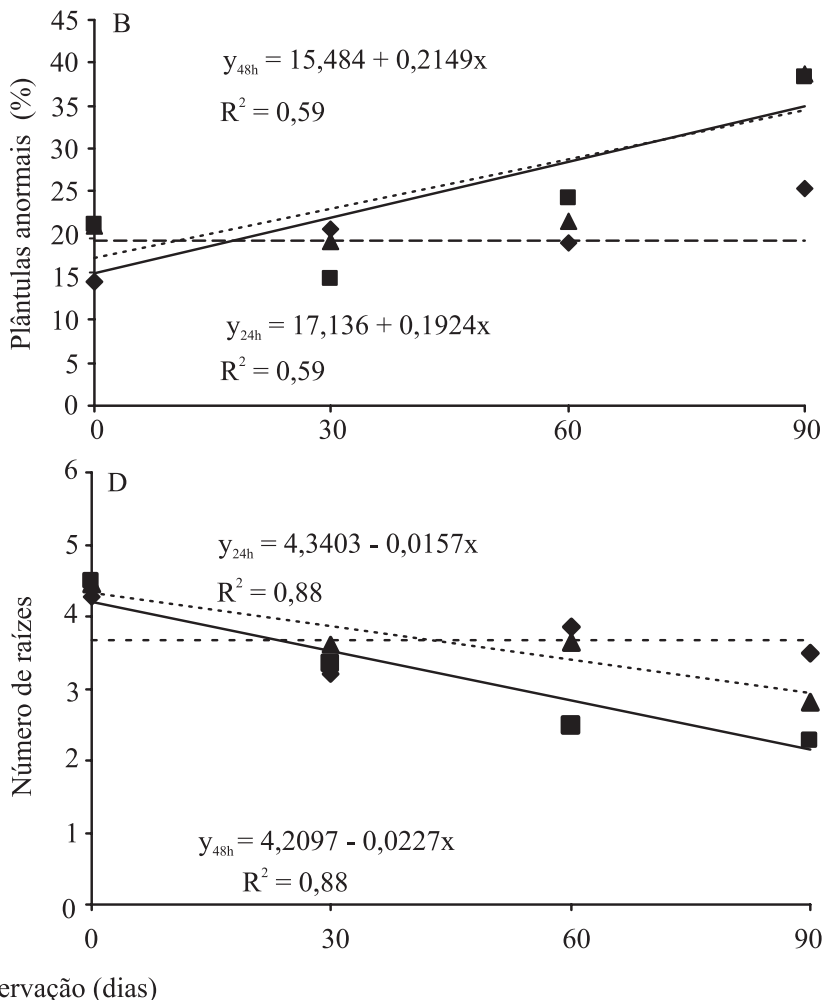

0 horas $\Delta 24$ horas 48 horas

Figura 2. Efeito do período de criopreservação (0, 30, 60 e 90 dias) e de dessecação das sementes (0, 24 e 48 horas) de pinhão-manso (Jatropha curcas) sobre a percentagem de germinação (A) e de plântulas anormais (B), a altura (cm) das plantas (C) e o número de raízes por planta (D). 
O conteúdo de umidade das sementes é um dos principais fatores que controlam a criopreservação (Hoekstra et al., 2001; Walters et al., 2004). Para sementes ortodoxas, recomenda-se conteúdos de umidade abaixo de $10 \%$; porém, o intervalo de umidade favorável para o congelamento difere entre as espécies. Sementes de mamona (Ricinus communis L.) foram danificadas e tiveram sua viabilidade reduzida quando criopreservadas com mais de $12 \%$ de umidade; no entanto, não houve redução na germinabilidade das sementes com teores de água entre 4 e $10 \%$, que foram mais adequados à criopreservação (Almeida et al., 2002). Castro et al. (2001) determinaram que o intervalo de umidade favoravel à criopreservação em sementes de urucum (Bixa orellana L.) situa-se entre 6 e 12\%, em virtude de que esses teores não terem alterado significativamente a viabilidade das sementes, que apresentaram percentual de germinação de $87 \%$.

De acordo com Crane et al. (2003) e Volk et al. (2006), sementes com conteúdos elevados de óleo são mais suscetíveis a injúrias e danos físicos causados por exposições a baixas temperaturas. Segundo os autores, baixas temperaturas podem cristalizar lipídeos durante a conservação das sementes. Portanto, no momento do congelamento, espera-se que ocorra interação entre os teores de umidade e de óleo das sementes, quanto à viabilidade, embora as razões dessa interação ainda não sejam conhecidas.

Em relação ao período de criopreservação, Almeida et al. (2002) não observaram redução da viabilidade de sementes de mamona criopreservadas por 60 dias. Goldfarb et al. (2010), ao analisar sementes de pinhão-manso sem levar em consideração seu teor de umidade, relataram que as sementes, após 90 dias de exposição ao nitrogênio líquido, mantiveram percentual de germinação estável, como observado em Prunus avium L. por Chmielarz (2009). Batista (2000) verificou aumento na percentagem de germinação de sementes de gergelim (Sesamum indicum L.) imersas em nitrogênio líquido. Entretanto, em algumas espécies de leguminosas ocorre redução na viabilidade de sementes criopreservadas por períodos prolongados (Almeida et al., 2000).

A percentagem de germinação apresentou melhores resultados quando as sementes foram criopreservadas com sua umidade inicial, com média de $70 \%$. Teores de umidade abaixo de $8 \%$ diminuíram a sobrevivência das sementes, o que indica que elas podem ser criopreservadas com a umidade inicial de quando são colhidas (em torno de 8-9\%), e que é possível a obtenção de sementes com elevada qualidade após 90 dias de criopreservação. Almeida et al. (2002), em estudos com R. communis, concluíram que as sementes de mamona podem ser criopreservadas com a umidade de colheita.

Nas plântulas provenientes de sementes expostas ao nitrogênio líquido com umidade de 8,3\%, não foram observados efeitos dos períodos de criopreservação sobre a percentagem de plântulas com anormalidades (Figura 2). Apesar do baixo coeficiente de determinação $\left(\mathrm{R}^{2}=0,59\right)$ das sementes com umidade de $8,3 \%$, houve crescimento linear na percentagem de plântulas anormais, com o aumento do tempo de exposição ao nitrogênio líquido, com média de 40,6\%, após 90 dias de armazenamento. Esse aumento expressivo também foi evidenciado no lote de sementes com umidade de $6,9 \%$, o qual, ao final de 90 dias de criopreservação, apresentou média de 39,7\% de anormalidade. Almeida et al. (2000) observaram que sementes com elevado teor de óleo são mais suscetíveis à injúria e a danos físicos causados pela exposição a baixas temperaturas.

Houve diminuição no tamanho das plântulas pelo aumento no período de criopreservação (Figura 2). As plântulas provenientes do lote testemunha apresentaram maior altura da parte aérea, com média de 4,8 cm. As sementes com umidade de 8,3\% apresentaram, ao final de 90 dias de criopreservação, plântulas com média de 2,9 cm. Esse efeito também foi obtido nas sementes com umidade de 6,4 e 5,9\% (dessecadas por 24 e 48 horas, respectivamente), que apresentaram plântulas com altura média de 2,0 e $1,9 \mathrm{~cm}$, respectivamente. A redução na altura das plântulas pode ser atribuída à redução do metabolismo causada pela exposição dos materiais vegetais a temperatura subzero. Martins et al. (2009), ao avaliar o comportamento de sementes de ipê-roxo (Tabebuia impetiginosa), concluíram que as sementes são tolerantes ao congelamento $\left(-196^{\circ} \mathrm{C}\right)$ desde que o teor de água seja de $4 \%$. Nessas condições, as sementes, após 240 dias de criopreservação, produziram plântulas com altura inferior às da testemunha. Rocha et al. (2009) também observaram que o vigor, expresso pelo comprimento 
das plântulas provenientes de sementes de algodão (Gossypium hirsutum L.) criopreservadas, reduziuse de 22 para 2,0 cm. Meletti et al. (2007), ao avaliar acessos de Passiflora spp., demonstraram que plântulas provenientes de sementes criopreservadas por dez dias, com $20 \%$ de umidade, não diferiram da testemunha quanto ao comprimento da parte aérea.

A percentagem de germinação de plântulas com anormalidades manteve-se estável nas sementes criopreservadas por 90 dias, com umidade inicial. Esse comportamento também foi observado na variável número de raízes, que apresentou, ao final do período de congelamento, três raízes por plântula, não tendo ocorrido ajustes significativos (Figura 2). Portanto, o número de raízes por plântula proveniente de semente com umidade em torno de $8 \%$ não foi afetado pelo tempo de exposição ao congelamento. Contudo, nas sementes dessecadas por 24 e 48 horas, houve redução no número de raízes, com média de 1,9 e 2,2 raízes por plântula, respectivamente. Como essa redução também foi verificada na variável percentagem de germinação, observa-se que a criopreservação das sementes com umidade entre 5-6\% afeta sua qualidade.

A qualidade e o número de raízes em pinhão-manso também podem variar de acordo com o substrato no qual se encontra. Nunes et al. (2008) observaram que a maior e a menor concentração de sacarose no meio de cultura afetam a produção de raízes de plântulas de pinhão-manso oriundas de sementes germinadas in vitro. Camillo et al. (2009), em trabalho com criopreservação de sementes de dendezeiro (Elaeis guineensis), obtiveram taxa de germinação de $90 \%$, após 21 dias de crioarmazenamento. Esses autores observaram raízes primárias bem desenvolvidas e ausência de plântulas anormais ao final da avaliação, o que mostra o potencial das técnicas de criopreservação na conservação de sementes de certos genótipos de dendezeiro, sem comprometer sua viabilidade. Os resultados obtidos no presente trabalho corroboram os de Walters et al. (2004), quanto ao limite de umidade confiável para manutenção da qualidade de sementes armazenadas em nitrogênio líquido, que pode variar entre diferentes espécies.

$\mathrm{Na}$ avaliação da viabilidade dos embriões, os padrões de coloração observados variaram de vermelho intenso, em regiões danificadas, a branco, nas regiões mortas (Figura 3). A inviabilidade dos embriões pode ser atribuída à incidência de injúria nos tecidos da semente causada pela exposição à temperatura extrema. Steponkus (1984) e Walters et al. (2004) relataram que os danos mais significativos causados pelo congelamento estão relacionados ao deficit hídrico. Essas injúrias, em geral, são alterações na semipermeabilidade ou no rompimento da membrana plasmática. Chandel et al. (1995), ao avaliar a tolerância à dessecação, seguida de imersão em nitrogênio líquido, em sementes de cacau (Theobroma cacao L.), observaram redução na sua viabilidade. Essa redução foi comprovada por estudos ultraestruturais, que indicaram rompimento das membranas celulares durante a dessecação e o congelamento das sementes.

Nas plântulas que apresentaram anormalidades, observou-se diferentes padrões de desenvolvimento. A análise histológica indicou anormalidade externa e interna. As folhas normais (Figura 3) apresentaram mesofilo dorsiventral com parênquima paliçádico voltado para a face adaxial e parênquima lacunoso para a face abaxial da folha, o qual apresentou células isodiamétricas com paredes retas. Nessas folhas, é possível observar feixes vasculares com organização colateral, nervura principal proeminente e feixe vascular diferenciado. A epiderme apresenta células com formato tabular e paredes retas. Não foi possível fazer a distinção entre os dois tipos de parênquima clorofiliano, nas folhas com anormalidades. O mesofilo dessas folhas apresenta-se desorganizado com células em formato irregular e paredes sinuosas, o que torna impossível a visualização de feixes vasculares organizados.

Morfologicamente, as plântulas com germinação anormal apresentaram características como: cotilédones que permaneceram aderidos e atrofiados, tendo dificultado o crescimento do epicótilo; cotilédones que permaneceram aclorofilados; plântulas que desenvolveram apenas o hipocótilo; e formação de calos na face adaxial dos cotilédones e na base do hipocótilo, que se multiplicaram e romperam a epiderme adaxial da folha (Figura 3). A formação de calos foi a anormalidade observada com maior frequência nas folhas das plântulas provenientes de sementes criopreservadas. Em algumas folhas com anormalidades, não foi possível distinguir nervura principal e invaginações da epiderme em direção ao mesofilo indiferenciado. 

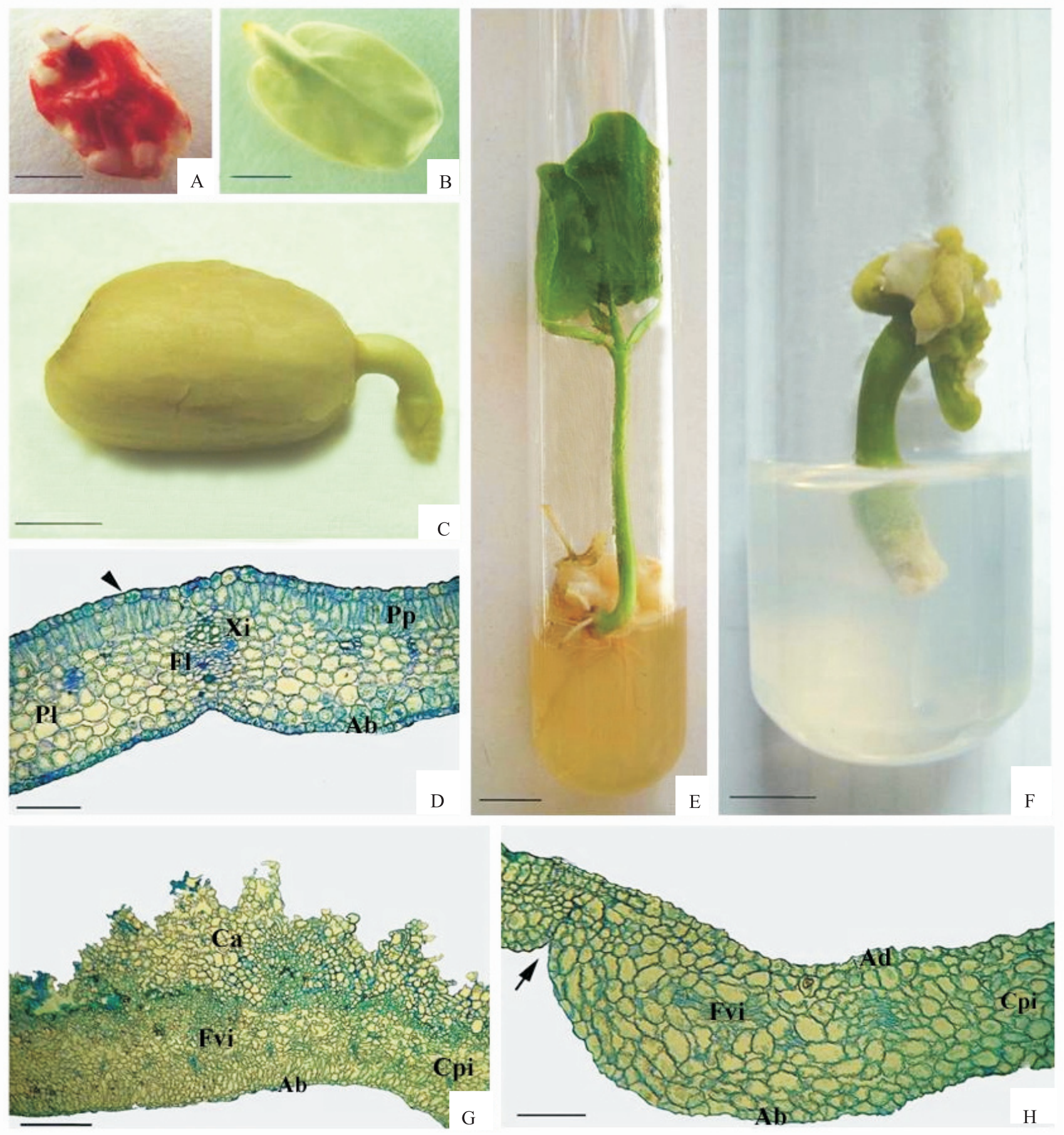

Figura 3. Efeito da dessecação e da criopreservação nas sementes de pinhão-manso (Jatropha curcas). A, danos físicos no embrião criopreservado (barra $=1 \mathrm{~cm}$ ); $\mathrm{B}$, embrião inviável após exposição ao nitrogênio líquido (barra $=1 \mathrm{~cm}$ ); $\mathrm{C}$, germinação com emissão da radícula com curvatura geotrópica positiva (barra $=1 \mathrm{~cm}$ ); D, secção transversal de folha normal de plântula proveniente de semente criopreservada (barra $=100 \mu \mathrm{m})$ - Fl, floema; Xl, xilema; Pp, parênquima paliçádico; $\mathrm{Pl}$, parênquima lacunoso; $\mathrm{Ab}$, face abaxial e face adaxial (seta); E, plântula normal (barra $=1 \mathrm{~cm}$ ); $\mathrm{F}$, plântula anormal (barra $=1 \mathrm{~cm}) ; \mathrm{G}$, secção transversal de folha anormal (barra $=200 \mu \mathrm{m})-\mathrm{Ca}$, calo; Fvi, feixe vascular indiferenciado; Cpi, células com parede irregular; H, Secção transversal de folha anormal (barra $=200 \mu \mathrm{m})$ - Ad, face adaxial. 


\section{Conclusões}

1. Sementes de pinhão-manso são tolerantes à dessecação e mantêm sua viabilidade mesmo com teor de água reduzido abaixo de valores críticos.

2. Sementes de pinhão-manso mantêm sua viabilidade elevada quando criopreservadas com umidade em torno de $8 \%$, sem necessidade de maior dessecação.

3. A dessecação das sementes de pinhão-manso, associada a períodos prolongados de exposição a nitrogênio líquido, afeta negativamente a viabilidade das sementes, danifica células e tecidos foliares e causa anormalidade de plântulas.

\section{Referências}

ALMEIDA, F. de A.C.; MORAIS, A.M. de; CARVALHO, J.M.F.C.; GOUVEIA, J.P.G. Crioconservação de sementes de mamona das variedades nordestina e pernambucana. Revista Brasileira de Engenharia Agrícola e Ambiental, v.6, p.295-302, 2002.

ALMEIDA, F. de A.C.; VILLAMIL, J.M.P.; GOUVEIA, J.P.G. de. Efecto de la crioconservación sobre la germinación de semillas de leguminosas. Revista Brasileira de Produtos Agroindustriais, V.2, p.67-71, 2000.

BATISTA, R.C. Cultivo in vitro e criopreservação de sementes de gergelim (Sesamum indicum L.). 2000. 83p. Dissertação (Mestrado) - Universidade Federal da Paraíba, Campina Grande.

BERCHMANS, H.J.; HIRATA, S. Biodiesel production from crude Jatropha curcas L. seed oil with a high content of free fatty acids. Bioresource Technology, v.99, p.1716-1721, 2008.

BLACK, M.; OBENDORF, R.L.; PRITCHARD, H.W. Damage and tolerance in retrospect and prospect. In: BLACK, M.; PRITCHARD, H.W. (Ed.). Desiccation and survival in plants: drying without dying. Wallingford: CABI, 2002. p.367-382.

CAMILlO, J.; LUIS, Z.G.; SCHERWINSKI-PEREIRA, J.E. Tolerância de sementes de dendezeiro à criopreservação. Pesquisa Agropecuária Brasileira, v.44, p.211-215, 2009.

CARVALHO, C.R.; CLARINDO, W.R.; PRACA, M.M.; ARAUJO, F.S.; CARELS, N. Genome size, base composition and karyotype of Jatropha curcas L., an important biofuel plant. Plant Science, v.174, p.613-617, 2008.

CARVALHO, J.E.U. de; MÜLLER, C.H. Níveis de tolerância e letal de umidade em sementes de pupunheira, Bactris gasipaes. Revista Brasileira de Fruticultura, v.20, p.283-289, 1998.

CASTRO, A.A.; MATA, M.E.R.M.; BRAGA, M.E.D. Teor de umidade limite para crioconservação de sementes de urucum (Bixa orellana L.). Revista Brasileira de Corantes Naturais, v.5, p.17- 22, 2001.

CHANDEL, K.P.S.; CHAUDHURY, R.; RADHAMANI, J.; MALIK, S.K. Desiccation and freezing sensitivity in recalcitrant seeds of tea, cocoa and jackfruit. Annals of Botany, v.76, p.443-450, 1995.

CHMIELARZ, P. Cryopreservation of dormant orthodox seeds of forest trees: mazzard cherry (Prunus avium L.). Annals of Forest Science, v.66, p.405p9, 2009.

CRANE, J.; MILLER, A.L.; VAN ROEKEL, J.W.; WALTERS, C. Triacylglycerols determine the unusual storage physiology of Cuphea seed. Planta, v.217, p.699-708, 2003.

EDMOND, J.B.; DRAPALHA, W.J. The effects of temperature, sand and soil, and acetone on germination of okra seed. Proceedings of the American Society for Horticultural Science, v.71, p.428-443, 1958.

ENGELMANN, F. Use of Biotechnologies for Conserving Plant Biodiversity. Acta Horticulturae, v.812, p.63-82, 2009.

FERREIRA, A.G.; BORGHETTI, F. Germinação: do básico ao aplicado. Porto Alegre: Artmed, 2004. 323p.

GOLDFARB, M.; DUARTE, M.E.M.; MATA, M.E.R.M.C. Armazenamento criogênico de sementes de pinhão manso (Jatropha curcas L.) Euphorbiaceae. Biotemas, v.23, p.27-33, 2010.

HELLER, J. Physic nut (Jatropha curcas L.): promoting the conservation and use of underutilized and neglected crops. Rome: International Plant Genetic Resources Institute, 1996. 66p.

HOEKSTRA F.A.; GOLOVINA E.A.; BUITINK J. Mechanisms of plant desiccation tolerance. Trends in Plant Science, v.6, p.431-438, 2001.

KERMODE, A.R.; FINCH-SAVAGE, B.E. Desiccation sensitivity in orthodox and recalcitrant seeds in relation to development. In: BLACK, M.; PRITCHARD, H.W. (Ed.). Desiccation and survival in plants: drying without dying. Wallingford: CABI, 2002. p.149-184.

MARTINS, L.; LAGO, A.A. do; ANDRADE, A.C.S. de; SALES, W.R.M. Conservação de sementes de ipê-roxo (Tabebuia impetiginosa (Mart. ex DC.) Standl.) em nitrogênio líquido. Revista Brasileira de Sementes, v.31, p.71-76, 2009.

MEDIA CYBERNETICS. Image-Pro Plus: images database user guide for Windows. Version 4.5. Silver Spring: Media Cybernetics, 2001.

MELETTI, L.M.M.; BARBOSA, W.; VEIGA, R.F.A.; PIO, R. Crioconservação de sementes de seis acessos de maracujazeiro. Scientia Agraria Paranaensis, v.6, p.13-20, 2007.

MURASHIGE, T.; SKOOG, F. A revised medium for rapid growth and bioessays with tobacco tissue cultures. Physiology Plantarum, v.15, p.473-479, 1962.

NUNES, C.F.: PASQUAL, M.; SANTOS, D.N. dos; CUSTÓDIO, T.N.; ARAÚJO, A.G. de. Diferentes suplementos no cultivo in vitro de embriões de pinhão-manso. Pesquisa Agropecuária Brasileira, v.43, p.9-14, 2008.

OPENSHAW, K. A review of Jatropha curcas: an oil plant of unfulfilled promise. Biomass and Bioenergy, v.19, p.1-15, 2000.

PACHECO,A.C.; CASTRO, P.R.C.;APPEZZATO-DA-GLORIA, B. Aspectos anatômicos do enraizamento da videira muscadínia 
(Vitis rotundifolia Michx.) através de alporquia. Scientia Agricola, v.55, p.210-217, 1998.

REGRAS para análise de sementes. Brasília: Ministério da Agricultura, Pecuária e Abastecimento, 2009. 365p.

ROBERTS, E.H. Predicting the storage life of seeds. Seed Science and Technology, v.12, p.499-514, 1973.

ROCHA, M. do S.; MATA, M.E.R.M.C.; CARVALHO, J.M.F.C.; LOPES, K.P. Crioconservação de sementes de algodão. Revista Brasileira de Engenharia Agrícola e Ambiental, v.13, p.312-318, 2009.

SATURNINO, H.M.; PACHECO, D.D.; KAKIDA, J.; TOMINAGA, N.; GONÇALVES, N. P. Produção de oleaginosas para o biodiesel. Informe Agropecuário, v.26, p.44-74, 2005.
STEPONKUS, P.L. Role of the plasma membrane in freezing injury and cold acclimation. Annual Review of Plant Physiology and Plant Molecular Biology, v.35, p.543-584, 1984.

VOLK, G.M.; CRANE, J.; CASPERSEN, A.M.; HILL, L.M.; GARDNER C.; WALTERS, C. Massive cellular disruption occurs during early inhibitions of Cuphea seeds containing crystallized triacylglycerols. Planta, v.224, p.1415-1426, 2006.

WALTERS C.; WHEELER, L.; STANWOOD P.C. Longevity of cryogenically stored seeds. Cryobiology, v.48, p.229-244, 2004.

WEBSTER, G.L. Classification of the Euphorbiaceae. Annals of the Missouri Botanical Garden, v.81, p.3-32, 1994.

ZONTA, E.P.; MACHADO, A.A. Sanest: sistema de análise estatística para microcomputadores. Pelotas: UFPel, 1984. 138p.

$\overline{\text { Recebido em } 18 \text { de janeiro de } 2011 \text { e aprovado em } 22 \text { de julho de } 2011}$ 